\title{
Traversing temporalities at end-of-life: \\ Mobilizing narratives with imagination and aesthetic sensibilities
}

\author{
Stephanie M. Pangborn, ${ }^{1}$ Lynn M. Harter ${ }^{2}$ \\ ${ }^{1}$ Department of Communication, Hope College, Holland, MI; ${ }^{2}$ School of Communication Studies, Ohio University, Athens, OH, USA
}

\begin{abstract}
We bring into focus the role of the imagination and aesthetics in narrative sensemaking, particularly as it informs end-of-life care, in this engaged and ethnographically-inspired research project. To begin, we detail a brief history of hospice and situate our work amid literature on storytelling and health communication. We then introduce readers to Grace Hospice's Creatively-Inspired Experiences (CIEs), opportunities for patients and their family members to engage in artful interactions, which was integrated within volunteer services as means of offering care beyond basic measures for comfort and companionship. Motivated by curiosities about how storytelling arises and functions in contexts often characterized as the end, this project illustrates the capacity of storytelling to traverse the temporalities of life stories while meaningfully responding to the challenges of relational connection and narrative continuation in hospice contexts. Specifically, findings suggest that narrative imagination and aesthetic sensibilities act as mobilizing resources, enabling stories to affect relationships by transcending chasms, nurturing mindfulness and presence, and cultivating legacies and tomorrows.
\end{abstract}

\section{Introduction}

Pete's advanced stages of Parkinson's disease caused incredible difficulties in his communicative efforts. He had

Correspondence: Stephanie M. Pangborn, Department of Communication, Hope College, Martha Miller Center 122, 257 Columbia Avenue, Holland, MI 49423, USA. E-mail: pangborn@hope.edu

Conflict of Interest: The Authors declare no potential conflict of interests.

Key words: Storytelling; Narrative Imagination; Aesthetics; Temporality; Hospice.

To the hospice organization that trusted us to contribute to the holistic care of their patients, thank you beyond measure for enabling these experiences to be a part of our professional journeys. To the patients and families who shared their lives with us, we offer our heartfelt gratitude - your resiliency and legacies continue to inspire our work.

Conference Presentation: A former version of this manuscript was accepted for presentation at the 2015 National Communication Association conference in Las Vegas, NV.

Received for publication: 26 October 2019.

Accepted for publication: 12 January 2020.

This work is licensed under a Creative Commons Attribution NonCommercial 4.0 License (CC BY-NC 4.0).

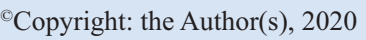

Licensee PAGEPress, Italy

Qualitative Research in Medicine \& Healthcare 2020; 4:1-12

doi:10.4081/qrmh.2020.8642 lost much of his hearing, his attempts to control his constant tremors demanded most of his energy and attention, and his voice was muffled and quiet. His body also suffered from multiple other diagnoses that challenged his overall wellbeing, but those were never explained to me and I did not feel the need to ask. He lived alone in a room at a full-time care facility, receiving daily hospice visits from his nurse as part of his care plan. Otherwise, he spent his time alone. The edges of his room, which was kept in orderly fashion to diminish the risk of falls, were adorned with artifacts from what appeared to be a full and vibrant life (e.g., photographs featuring seven decades worth of smiles and relationships, family pottery passed down through generations, greeting cards, antique clocks, and books with worn and dusty covers) and presented a striking contrast to his crisply tucked bed linens, empty moss green burlap couch, and dining room table with one wooden chair. His sister requested hospice volunteer visits, hoping that company would alleviate his depression and her own guilt for not being able to take care of him on a regular basis. After my first discouraging visit with him, she called to suggest that his love of country music might be my best bet in forming any sort of connection. A simple set of noise-cancelling earbuds and his tunes - that's all it took. Our visits and his daily life in my absence were transformed. Pete was enlivened by the sounds of Reba, Dolly, and Johnny Cash. Joy emanated from his body in those moments; it was miraculous, really. Previously hesitant to interact because of his physical limitations and insecurities therein, he found the rhythm he needed to dance in his chair, thumbs effortlessly slipped into his belt loops, and southern-twang shoulder shrugs, as he often exclaimed: 'I'm dancing now!'His an- 
imated spirit demonstrated that he felt known, seen, and worthy of relationship, even though the corporeal effects of this disease tempted him to believe otherwise. (First author fieldnotes).

There are two basic essential needs of dying patients: i) to allow for hope ... not the same hope for cure treatment or prolongation of life and ii) a reassurance that they will not be deserted. ${ }^{1}$ Rather than viewing hope as an attitude or an outcome, Mattingly ${ }^{2}$ positioned hope as a relational practice that most centrally involves the practice of creating, or trying to create, lives worth living even in the midst of suffering, even with no happy ending in sight. In Pete's case, it was the formation of relationship rooted in a mutual appreciation for music that instilled something worth living for in a life otherwise perceived to be drastically diminished, one that had been given an estimated end date. Although southern tunes had no chance of curing the diseases of progressive decline continuously altering his body and abilities, his sister did claim that music saved the life he had left to live. His aesthetic spirit and vulnerability to imagine otherwise for himself enabled vivid performances of a life that still lingers with force in our minds and motivates our passionate pursuit of creative approaches to care.

Narratives are symbolic resources that temporally and spatially situate characters and motives, scenes, events, and action sequences through the process of emplotment. ${ }^{3}$ In the mundane and extraordinary moments, humans draw on and craft stories to make sense of life. Although communication scholars significantly influenced the narrative turn in health-related practice, ${ }^{4}$ scholars have yet to adequately attend to the poetic potential of narrative sensemaking and the conditions that cultivate the sharing and performing of lives and their stories. The use of a narrative lens for exploring the ways in which human beings understand and operate within complex social environments has grown exponentially, noted Andrews; ${ }^{5}$ yet, $[\mathrm{m}]$ ost of this work has not dwelled upon the machinations of human imagination in the production and interpretation of narrative. And here, we intervene.

Rather than gravitating toward spoken or written texts as much of communication scholarship does, we actively accept Sharf' ${ }^{6}$ urging that scholars pursue possibilities to be realized by communicative interactions that rely on multisensory forms. We join this conversation and illustrate the merits of an aesthetic approach to storytelling that includes but reaches beyond linguistic signifying practices. We bring into focus the role of the imagination in narrative sensemaking, particularly as it informs endof-life care. To begin, we offer a brief account of hospice care and situate our work amid literature on storytelling and health communication. We then introduce readers to Grace Hospice and its Creatively-Inspired Experiences (CIE), created and directed by the first author. The cou- pling of narrative theory and the aesthetic practices of CIE is instructive in illustrating the salience of temporality and creativity in narrative-based interventions in medicine and healthcare.

\section{The Narrative Shape of Hospice Care}

Hospice care envision [s] a world where everyone facing serious illness, death, and grief will experience the best that humankind can offer. ${ }^{7}$ Hospice services involve:

a coordinated program providing palliative care to terminally ill patients and supportive services to patients, their families, and significant others 24 hours a day, seven days a week. Comprehensive/case managed services based on physical, social, spiritual, and emotional needs are provided during the last stages of illness, during the dying process, and during bereavement by a medically directed interdisciplinary team consisting of patients/families, health care professionals and volunteers. Professional management and continuity of care is maintained across multiple settings including homes, hospitals, long term care and residential settings. ${ }^{8}$

The American Hospice Foundation ${ }^{9}$ further explains that the patient is at the center of this interdisciplinary team approach to enhancing quality of life: You tell the team about your story, your hopes your values. You decide what kind of care is not enough and what is too much. Your hospice team members use their experience and skills to carry out your wishes.

Those whose lives and families have been cared for within the hospice approach, think of it as caregiving in the finest tradition: care that is both competent and compassionate. ${ }^{8}$ To truly understand hospice, and its value, requires that we accept the reality of death, a reality that we have been trained to ignore because of the dis-ease we feel in communicating about our mortality ${ }^{10}$ and the discomfort often experienced by the chasms that lifelimiting illness imposes in relationships. ${ }^{11}$ Western culture's delusional misunderstanding that medicine is an infallible science fuels social hesitance to accept hospice care as a legitimate and necessary approach to caring for the holistic pain experienced by dying persons and those who love them. In fact, choosing hospice is often regarded as frightening, socially unacceptable, or as giving up, encouraging people instead to do everything to avoid death without serious consideration of the consequences therein. ${ }^{10}$ In 1967, after nearly two decades of witnessing patients endure these burdensome consequences and learning from the stories they shared, Cicely Saunders founded the first hospice, St. Christopher's, in London; the roots of its inception characterize hospice as a narratively-inspired form of care. The hospice movement was (and arguably, still is) considered to be a revolutionary approach to care because it challenges 
the mind-body dualism of modern medical practice and prioritizes people and their stories. ${ }^{12}$

\section{Storytelling in Health-Related Contexts}

Narrative is at once a phenomenon worthy of inquiry and a theoretical perspective used to explore social phenomenon. ${ }^{4}$ Narrative theory positions storytelling as a legitimate form of reasoning: a knowledge producing resource enabling individuals to make sense of disruption and envision otherwise. ${ }^{3}$ We adopt a broad standpoint that encompasses personal stories, cultural and institutional scripts, and the storytelling process. We understand narratives as enactments of events, told from a particular point of view. We also conceive of storytelling as a performative act that shapes and is shaped by the discursive and material surround.

Storytelling is a symbolic resource used by humans to make sense of suffering and foster well-being. Frank ${ }^{13}$ compared a serious diagnosis to a loss of destination and map and characterized patients as wounded storytellers. Narratives account for misfortune, ascertain responsibility, and infer warrants for decisions made and future directions. ${ }^{14}$ While reckoning with illness, treatment, and what remains in the aftermath, patients and families also construct life and health legacies, revealing or sequestering storylines in effort to fulfill desired purposes. ${ }^{15,16}$

In Arthur Frank's ${ }^{17}$ Letting Stories Breathe, he explained that, [s] tories animate human life; that is their work. Stories work with people, for people, and always stories work on people, affecting what people are able to see as real, as possible, and as worth doing or best avoided. We are reminded here that our stories are consequential - informing our sense-making processes and giving form to our ongoing performances of self and relationship. Our stories animate ... instigate ... mobilize, ... remind us that we have to live with complicated truths, and offer a plot that makes some particular future not only plausible but also compelling. In acknowledgement of their capacity to move us in all of these ways, we have much to gain in further exploration of the narrative resources that cultivate occasions for our stories.

\section{Narrative Resources}

A central feature of storytelling is its ability to deal simultaneously with continuity and disruption. Crafting and consuming stories, especially in response to disruption and the relational disconnection that ensues, requires people to exercise their imagination. Coupling narrative sensibilities with the imagination emphasizes the importance of temporality. ${ }^{5} \mathrm{~A}$ fundamental part of the narrating process at end-of-life is the and then - the constructing of a sequence of elements to understand the complexities of current experiences ${ }^{18}$ as well as resisting temptation to finalize lives and limit legacies. ${ }^{19} \mathrm{Ac}$ knowledging temporality encourages the consequential linking of events, demonstrating the human capacity to make sense of present conditions while being both anchored by history and transported into the future. Narrators who exercise their imagination are artful in piecing together fragments of their life stories. In this way, storytelling involves what Andrews described as time travelling, or movement between the past and present and the past again as they revisit memories in light of changing circumstances and envision otherwise for their futures. However, in the hospice context, when a patient has been given a terminal diagnosis and chosen to forgo curative treatments, the and then gets complicated for individuals and relationships.

People's lives are defined by what is both included and overlooked in the telling of stories, a process that is nonetheless socially conditioned. As noted by Andrews ${ }^{5}$ Imagination, like knowledge, does not come out of nothingness, but is a creative synthesis which emanates from a particular location. Envisioning otherwise is a meaningmaking process fraught with difficulty. The practice of medicine is intricately linked to deeply entrenched cultural assumptions and normative conceptions. Cultural scripts (e.g., technology is progress) institutionalize patterns of care and normative expectations (e.g., the eradication of disease).${ }^{20}$ Forgoing curative treatments is a difficult choice, as it is often perceived as losing hope and giving up. Too often, these characterizations lead individuals to submit to narrative foreclosure, an inability to see one's experience as having any significance beyond itself. ${ }^{19}$

Fostering storytelling through creative programming is a practice full of possibility. Yet, communication scholars generally gravitate toward spoken or written texts. Sharf ${ }^{6}$ urged scholars to be careful about over-privileging the verbal such that other important sensory contributions are not recognized and credited. As she suggested, there is much to be discovered in the potential of creative forms of narrative, as they might open dialogue in ways that better reflect the unique experiences of suffering individuals. In light of the relational and communicative challenges patients and families face in hospice, the pursuit of new narrative resources that capitalize on the aesthetic, embodied nature of experience is one way of providing compassionate, humanizing care. Through the sharing and performance of the continued narrative new selves emerge, allowing relationships to move beyond the limiting tropes of illness. ${ }^{15}$

As individuals whose lives were profoundly affected by hospice experiences, we (both authors) recognize the capacity of stories and an aesthetic spirit in moving beyond the difficulties surrounding end-of-life care. The first author's grandfather served as a hospice chaplain and died as a hospice patient. The second author's mother graduated from hospice care when her health stabilized and her father's life ended in hospice care. We 
both acknowledge that while hospice workers delivered incredible care to our families, we deeply longed for something more. This personal desire, inspired by our narrative, aesthetic, and pragmatic sensibilities, led us to explore the integration of multi-sensory storytelling experiences in hospice. Certainly, we are not the first to acknowledge that interventions beyond the scope of traditional Western medicine have the potential to affect patients' holistic well-being in profound ways. Complementary and Alternative Medicines (CAM) - professionally-directed integration of experiences such as art, music, massage, meditation, aromatherapy, and acupressure, among others - are designed to address the mind, body, and spirit connection in healing and have been found to reduce patients' symptoms of pain, depression, anxiety, and fatigue. ${ }^{21}$ While the goal of CAM is to enhance quality of life and comfort, thereby aligning perfectly with the hospice philosophy, the Medicare Hospice Benefit does not require it of hospice interdisciplinary teams. Our family hospice experiences, as is the case for individuals enrolled in most hospice organizations in the United States, did not include such therapies for our loved ones. In fact, more than $70 \%$ of hospice organizations do not employ a professional CAM therapist; of those that do, only $53 \%$ have an art therapist on staff and only $22 \%$ have a music therapist. ${ }^{21}$

A lack of paid interdisciplinary team members primarily dedicated to enabling patients and families to experience the socioemotional benefits of narrative occasions conditioned by art and music should not keep people from engaging in creatively-inspired communication and experiencing the relational healing therein. Motivated by Frank, ${ }^{17}$ we focus attention on what stories do for people, exploring how stories breathe life into living. Specifically, we focus on the question: How do multisensory stories, and the creative conditions in which they arise, function in the hospice context? In answering this question, we extend health narrative scholarship by emphasizing the practical value of narrative theory and an imaginative, aesthetic orientation as resource for meaningful storying occasions (i.e., telling, witnessing, sharing, and performing).

\section{Research Design}

CIE were comprised of activities that relied on aesthetic engagement (e.g., video life legacies, painting, drawing, photography, music, and poems) to foster conditions for performances of self and narrative imagination within relationships. These additions to Grace Hospice's approach to caring for the holistic needs of individuals were theoretically-grounded opportunities to enrich hospice patients' and their families' experiences as they made sense of what can be a very difficult experience. CIE were explained to patients and family members during their initial hospice enrollment meeting. Oftentimes, it took more time for patients and families to embrace these opportunities and they usually sought them out in conversation with their nurse, social worker, or volunteer coordinator at a later date. Upon their expressed desire to participate, the first author and volunteer coordinator met with the participants to identify activities of interest and selected a volunteer well-suited for the particularities of the given context.

Worth noting here is that all CIE volunteers were required to attend a hospice volunteer training and interactive seminar led by the first author in which the purpose and theoretical foundations of CIE were described in detail. At the outset of the project, too, during one of their regularly scheduled meetings all members of the hospice interdisciplinary team were provided an in-depth explanation of CIE, its purpose, and the theoretical foundations upon which it was designed. Specifically, in discussion with care providers, the first author emphasized the important role they each could play in efforts to enhance holistic care by identifying patients and families who might benefit from CIE engagement as well as relying upon these communicative sensibilities as they sought to build meaningful relationships with their patients. Only one month following CIE implementation, twelve care providers (who verbally committed to intentionally prioritize CIE as a meaningful part of holistic care) and five volunteers dedicated solely to CIE (each kept an average of three patients with whom they regularly visited, assignments obviously shifting with the nature of hospice in that they would meet with new patients after others with whom they had visited were no longer alive) were engaged as participants. Of the patients who chose to engage in CIE, some had family members involved, while others did not. Throughout the life course of this project, participation in CIE grew with encouraging trajectory. Keeping track of the number of patients, family members, volunteers, and care providers engaged in CIE became a trivial task as we witnessed participants in the project become advocates of these creative narrative resources, inspiring countless others to rely upon similar sensibilities in their work and relationships.

Exiting the field upon completion of an ethnographic project is a challenging task, especially when the experience emotionally enmeshes you in the lives of participants and reveals the necessity of your engaged work. The difficulties we experienced in closing the door to this specific journey were greatly alleviated by the knowledge that we offered something of value to the organization and the people it serves. Grace continues to provide CIE and uses the training materials created for this project to educate volunteers and care providers about the value of creative narrative resources in the hospice setting. While we do not anticipate pursuing similar applied research projects with other hospice organizations, we do hope that Grace's capacity to infuse their organizational practices with these narrative sensibilities, even while con- 
tinuing to face the financial burdens inhibiting them from having CAM therapists on staff, will inspire other hospice teams to cultivate creatively-inspired communicative experiences of their own. As this project and numerous others have taught us, creative approaches to communicating in healthcare settings have tremendous capacity to enhance well-being and its practice need not be reserved for trained professionals.

\section{Setting}

The first author had previously worked at Grace Health System (note: an organizational pseudonym was chosen to maintain privacy of participants) - a large community-owned, not-for-profit health system with a full range of inpatient and outpatient services, including a hospice home. She relied upon her relationships with the CEO, staff members and care providers to secure access and approval for the creation of CIE as aligned with the organization's expressed desire to enhance its patient- and family-centered focus. Specifically, although they lacked the financial resources to hire CAM professionals to work integrated these experiences from therapeutic perspectives, as many hospice organizations do, Grace leadership and both authors were optimistic about the potential to be realized by training members of the volunteer force to draw upon narrative and aesthetic sensibilities in their interactions with patients and families. CIE were explicitly described as non-therapeutic, but still yet, intentional efforts to cultivate conditions for the well-being and experiences of patients and families to be enriched; they simply and profoundly infused the care setting with creative approaches to communication. After obtaining IRB approval, the first author, with the guidance of the second author who served as a mentor situated outside of the site of study, embarked upon a fifteen-month ethnographically-inspired journey aimed toward crystallizing various qualitative methods (e.g., participant observation, in-depth interviews, and creative analytic practices) ${ }^{22}$ in an effort to offer a rich, nuanced understanding of how storytelling functions in CIE.

\section{Discourse Collection}

As a participant researcher, the first author immersed herself within the setting in various ways: CIE implementation, recruitment and training of volunteers, and observation of and participation in the program. Further, she joined in weekly Interdisciplinary Team (IDT) meetings in which care teams discussed the comprehensive care plans of each patient and identified those who might most benefit from CIE participation. In the midst of ethnographic observation, the first author facilitated interviews with 3 patients, 4 family members, 5 volun- teers, and 5 care providers. These interviews were an essential component of the research process, as they enabled participants to retrospectively make sense of their experiences. ${ }^{23}$ Each one who chose to participate provided verbal consent for observation and written consent for interviews. In addition, each participant was given the option to have his/her name used in publications or to choose a pseudonym. The first author used a semistructured approach in facilitating the 18 interviews (17 participants were interviewed; one participant engaged in three separate interviews and two-family members requested to be interviewed together), inviting deep description and detail from interviewees. ${ }^{24}$ These conversations ranged from 30 to 90 minutes. Further, the artistic renderings of experience that emerged from CIE activities served as prompts for insightful conversations about the role of creative narrative forms.

In sum, 235 hours were spent involved in program development, implementation, observation, and interviews. The collected discourses included notes from meetings, patient/family visits, volunteer trainings, conversations, and interviews. These discourses resulted in more than 500 pages of fieldnotes, transcripts, and reflections and were supplemented with numerous multisensory artifacts created during CIE interactions.

\section{Discourse Analysis}

From the time the first author began fieldwork, she engaged in a flexible approach to constant comparative sensemaking to identify emergent ideas worthy of further development. ${ }^{25}$ Importantly, she engaged the discourse with narrative sensibilities. Following the lead of Reissman, ${ }^{26}$ she paid attention to stories told in interviews and performed in interaction, documenting her sensemaking processes in the form of reflections, theoretical memos, and conceptual maps. As she analyzed discourse, she was reminded of Boje's ${ }^{27}$ argument that narratives are not always structured linear accounts. Stories often unfolded, during CIE activities and in interviews, as fragments not nearly as tidy as often portrayed in academic theorizing. We resisted imposing counterfeit coherence ${ }^{27}$ on people's accounts while still highlighting concerns of interest to narrative scholars: temporality, disruption, plot, characters and their relations, and settings. The second author's outside vantage point provided an important perception check during data analysis. We discussed and debated various interpretations of what was evidenced in the discourse until reaching a consensus on the most viable, defensible, and interesting explanations.

Here, we present an artistic account that intermingles discourses and performances observed and experienced throughout the study with theoretical sensemaking about narratives and the social experiences of end-of-life. In doing so, our desire is to make rich contributions to com- 
munication theory and the practice of caring for individuals in health contexts as we demonstrate what it is that stories do: transcend relational chasms, nurture mindfulness and presence, and cultivate meaning-filled tomorrows. The vignettes we offer are firsthand accounts with individuals whose lives enlarged our capacity to envision humanizing potentials for end-of-life care. Alone, each one speaks volumes; together, they paint a vivid picture of possibility.

\section{Mobilizing Forces: Narrative Imagination and Aesthetic Sensibilities}

In a very real way, the act of travel enables people to experience anew. It offers a freedom to explore, to see, to sense. It presents fresh perspectives, invites inspirations, and cultivates moments turned into memories. Such was the case for Leon, a hospice patient living with lung cancer with a remaining life expectancy of only a few months. He and his wife, Eileen, living at the time with advanced Alzheimer's disease, and their daughter, Patty, participated in the CIE and engaged in conversations often prompted by family photographs and hymns the couple had recorded as newlyweds some fifty years prior. Below, we offer an extended vignette from the first author's fieldnotes to demonstrate the value of time travelling, a central concept in Andrews ${ }^{25}$ explanation of narrative imagination, to illustrate how storytelling allows participants to move between the past, present, and future.

The photographs Leon shared were vivid representations of his love and need for travel. In fact, he recounted his adventures with Eileen as being some of his fondest memories, as the two had stepped foot in each of the United States, with the lone exception of Hawaii. Leon emphasized the importance of this effort with a statement that continues to affect me, it's one thing to travel through some place and quite another to dwell in a moment on new terrain in appreciation of its beautiful value in your life.

Coincidentally, only a few days prior, my aunt asked me to join her on a trip to Hawaii. Due to my fond connection to Leon and realistic fear that he would die while I was away, I hesitated to accept her invitation. Leon urged me to go, to soak up the experience, to engrain its beauty in my mind. As I ran along the shores of Waikiki, toes in the water and sand, I thought about Leon. I dreamt of my grandfather. I revisited moments in my mind with many of my Grace patients and families. Each had left vivid markers on my life. Leon was right. Something magical happens when you allow yourself to travel to spaces and places - real and possible, past and future. Travelling introduces vantage points that reveal new potential to your present reality, your understanding of the past, and your tightly gripped hopes for tomorrows.

My run ceased that morning when the bottom of my bare foot made painful contact with a porous, weathered white rock with rough edges on the ocean floor. I picked it up, imagining the journey it had endured to achieve this condition - a condition with striking similarity to the storied accounts many hospice patients and family members had described to me. Quite frankly, the rock was a visual representation of things I had felt but never been able to describe, too. I kept this little piece of Hawaii to share with Leon.

Upon returning home, Leon's condition had declined. He could not get out of bed and his breathing was heavily labored. There wasn't much talking during our time together that day, but he managed to ask: 'How was the trip?' I smiled and showed him the rock. As I vividly described the gorgeous scenes I had encountered, he closed his eyes and handed the rock back to me. He said 'Put it on my foot ... let me feel it, like I'm there.'I could see that he was no longer confined to his bed but immersed in another place and time. I took his socks off and carefully rolled the rock along his toes and his heels. His eyes still closed and his smile even wider, he said: 'There, now my feet have touched Hawaii.' (First author fieldnotes).

Although tethered to a physical reality marked by diagnoses, medications, and medical equipment, an imaginative stance toward circumstance, ourselves, and one another, enables us to inhabit another dimension. The marrying of narrative sensibilities and our inherently human drive to imagine leads to what Bruner $^{3}$ referred to as trafficking in human possibilities rather than settled certainties. During the CIE experiences, hospice staff, volunteers, patients, and families transcended the place restricted by bodily decline and entered a space of enlarged potential for humanity to come into its fullest bloom. CIE taught us that even as individuals must traverse the rugged terrain of life, they also have the opportunity to explore what Andrews ${ }^{5}$ described as the creative tension between temporality and possibility and recognize life as threaded by ongoing change and perpetual becoming. Specifically, CIE served as a context in which to explore the critical function of imagination and narrative understanding. In these settings characterized by life-limiting illness, creative storytelling occasions functioned as a relational practice of hope that transcended chasms, nurtured mindfulness and presence, and cultivated meaningfilled tomorrows.

\section{Transcending Chasms}

The progression of terminal illness often imposes corporeal changes that complicate patients' communicative capacities, and shifts focus from the comfort of a previous life story to a perpetual fear [of] being unable to ever reconnect with the normal world. ${ }^{28(\mathrm{p} 110)}$ In response, a primary goal in end-of-life care should be to maximize the human potential for thriving. ${ }^{29}$ To humanize the journey from life to death, the imaginative pursuit of possibility 
is necessary, even in the midst of difficult, often exhausting, and painful realities that characterize the experience. The following vignettes illustrate the power of aesthetics to inspire narrative performances of self that are capable of fostering connections between people which transcend the divisive nature of their unique positionalities.

For 16 weeks, Bob had not touched the keys of his piano, previously an integral part of his everyday life. Doctors told him that his cancer had metastasized to his brain, that his memory and cognitive capacity would drastically and quickly fade. He refused to let the diagnosis steal this defining marker of who he and others knew him to be-a masterful pianist. After numerous CIE visits in which we relied on hymns played from the television stereo system, the disconnect between him and his craft was too much to take. He asked if I played, if I promised to not tell anyone if he played less than with excellence, and I responded yes to both of his extremely serious inquiries. He made me play first and the significance of what was at stake only enabled me to rely on the scales my grandmother had made me rehearse decades ago. I made it through only a minute before he motioned to the bench as if to ask permission to become himself again. Witnessing his initial hesitance and eventual eagerness as he reclaimed his art was one of the most beautiful things I had ever witnessed but was topped by the genuine grin of exuding happiness as his fingers lingered on the keys long after the notes faded. In this moment, Bob connected with one of the most meaningful parts of his life and I was invited to know a deeper dimension of his story. (First author fieldnotes).

Further, the corporeal conditions of some illnesses are to blame for the relational divides and communicative difficulties at end-of-life. A case in point is evident in one of our CIE volunteer's journals, which she kept for herself and shared with the first author during their one-on-one interview. Ashley, one of the most outgoing and artistically-inclined volunteers, had been selected to try to lift Joyce's spirits which had been very low for a long time following an Alzheimer's diagnosis and loss of ability to speak in coherent sentences. Joyce had simply quit speaking. Because Ashley had such a difficult time connecting with Joyce, she took it upon herself to journal about the experience in hope that it would inspire ideas or at least motivate her persistence. On July 25, she wrote: She did not like me at first ... I was a little offended ... I've been meeting with her for three weeks now, and she still won't make eye contact with me. ... I couldn't have possibly gotten a worse match. I am a talker. Joyce falls asleep. In her August $1^{\text {st }}$ entry, she described her approach to letting Joyce know she was committed to being with her even when it was difficult. She reflected, Whenever I talk, I sometimes think she tries to act like she is sleeping so I think she isn't listening, but I talk anyway. ... Just one little head nod would be fantastic. ... I feel like there hasn't' been much progress with our relationship. On August 16, though, initiated by Ashley's willingness to rub Joyce's back while holding her hand, the vibrancy of the outdoors, and a small yellow flower, things changed: It was a beautiful day... We sat at a bench to admire the waterfall and I noticed Joyce was admiring the potted flowers, so I picked one for her. ... she held it with a firm grip... and kept smelling it... she was so happy it was hers. Ashley was moved by the significance of these aesthetic moments shared in relationship, not predicated by words at all, and documented what she deemed an incredible moment. When it was time for Ashley to leave, she leaned down to say goodbye while looking Joyce in the eyes. This time, fully expecting her to look past me like she normally does, she moaned... reached out her hands and placed them on my cheeks. ... She pulled my face into her and kissed my forehead. Joyce kissed my forehead! (Excerpts from CIE volunteer journal).

Suffering and illness are not easily reduced to words; they are a lived reality, evoking intense feelings. As Janine, our volunteer coordinator described, when you work in hospice, it's just intense; we are in crisis; somebody's dying. Cultivating edifying relationships takes concentrated time and effort, and often a good dose of imagination, to overcome the corporeal communicative challenges imposed by diagnoses, disease progression, and disassociation from self and others that seems to temporarily alleviate partial aspects of pain. CIE relied on aesthetic moments and imaginative approaches to connecting with self and other, thereby enlarging narrative possibilities for relationship and ongoing significance of life as it approached its physically bound end. CIE experiences broke through constraints of what traditionally counts as communication, embracing multi-sensory storytelling with music, lyrics, color, photographs, poetry, paints, and artifacts. These artful moments invited patients to use creative resources in their efforts to perform their selves and connect with others - they were able to feel, see, and create a new within an experience marked by physical and socioemotional pain.

The miracle of imaginative and aesthetic narrative resources is realized when tangled scenes of life are made more intelligible ... their meanings as the matter of a clarified, coherent, and intensified or 'impassioned' experience..$^{30}$ In each of these examples, end-of-life circumstances previously perceived as isolating, for which individuals had no words sufficient in their ability to express the totality of their pain and desires, became shareable through new modes of multisensory experience. During CIE experiences, imagination and narrative sensibilities enabled patients to meaningfully reconnect to their lives and others in rich aesthetic fashion. Janine, the volunteer coordinator, emphasized the importance of these CIE opportunities by saying, it comes down, with 
these families and especially with the patients, to what 'really matters.' And these tools, these activities, these things matter ... it helps them to express that and especially experience that. Further, the art-based modalities revitalized individuals' dynamic spirits, addressing what Whalen ${ }^{31}$ described as the common intense desires at end-of-life: to leave lasting legacies, to thoughtfully review their lives, make peace with their losses, and deepen relationships with those whom would survive their death.

\section{Nurturing Mindfulness and Presence}

Hospice patients' families, friends, care professionals, and volunteers create a circle of witnesses who not only observe loved ones but also travel with them through their experience affirm [ing] what is eternal, valuable, meaningful, and sacred in their lives. ${ }^{13(\mathrm{p} 19)}$ Unfortunately, when the corporeal changes in bodies and minds affect individuals' abilities to interact with others, the building and maintaining of these relationships becomes a complex and challenging experience. Further, relationships within the medical setting are fraught with relational chasms characterized by extreme differences in perspectives toward the circumstance at hand. ${ }^{11}$ Freeing ourselves from preconceived notions that suggest hospice equates to the end - of life, relationship, meaning, possibility - invites us to imaginatively navigate relational challenges imposed by life-limiting illness and the anticipated grief of loss. When we rely on aesthetic dimension of communication and let it do its way ${ }^{30}$ with us, we learn to be present within painful and challenging moments which allows us to move in edifying directions with one another. As Dewey ${ }^{30}$ suggested of a growing life, so too may a relationship grow through pain and be, in effect, enriched by the state of disparity and resistance through which it has successfully passed.

CIE introduced a flexible foundation for patients and families to engage with one another. Using imagination and aesthetic experience as narrative resources allowed them to make some sense of a significant disruption, immersed in the here and now with an orientation toward possibility. Within these spaces, individuals moved beyond the immediacies of corporeal circumstances of illness to know the other and, in turn, themselves in new ways. These efforts achieved a transformation of time and space for patients and those in their circle of witnesses, an atmosphere made possible with what Reverend Rick, the spiritual care coordinator, called the ministry of presence which occurs when we choose to attend to the dying not by promising to alter their reality, but rather to say, for this moment, I'm going to be here, to journey with you. You're not going to be alone.

Unfortunately, not all individuals living with terminal illness have the luxury of being surrounded by their loved ones on a consistent basis as they approach death. Many of the Grace hospice patients lived in the organization's twenty-bed hospice home or a long-term healthcare facility in the community, which inevitably limited the time they were able to spend with family members and friends. For them, the urgency of a circle of witnesses beckoned staff members and volunteers to respond to moral moment $[s]^{32}$ in pursuit of dialogic relationship. CIE enabled individuals to cultivate these new relationships with the insight of imagination that opens doors to possibility, hope, and healing. ${ }^{30}$

For people like Libby, who had limited interactions with others, these relationships and moral moments experienced therein were integral to healing because, as Frank $^{32(\mathrm{p} 45)}$ suggested, the self has its origin and ongoing existence only in that realm. When Libby was enrolled in hospice services, she was living in a full-time healthcare facility, steadily losing weight, talking about death, seeing people from her past, and saying she was ready to go. Linda, her hospice nurse, learned that Libby had enjoyed a successful music career and thought that she might appreciate visits from a CIE volunteer.

I met Libby when I ventured down the long, lonely hallways to her room. Before I reached her door, my heart was tugged by her voice, strenuously and urgently repeating: 'Who knows me? I don't know who I am.' I knocked on her doorframe. 'Libby? Libby, may I visit with you for a while?' She turned in my direction. An immediate smile joined the previously sad scene. 'Libby?' I asked. 'Me? That's me? Do you know me? Come tell me if you know who I am.' I walked in and was immediately affected by the materials of her surround: an abundance of photographs pinned to a board on her wall, Kleenex boxes adorned with her handwritten notes to herself, red lip prints from the countless kisses she gave to her white teddy bear, colorful flowers cut from magazine pages and scattered on her bedside table, and Dove chocolate wrappers with quotes she found meaningful. Here, this woman was using all she had at her disposal to create something beautiful of a circumstance that imposed social suffering.

In our CIE visits, we celebrated the stories of her life as she narrated them, prompted by photographs, newspaper clippings, and songs from her past that held special meaning. We talked about playing the piano and singing and she tried to help me expand my range because I struggled to hit the low notes of her favorite song, Danny Boy.

Every visit started the same 'Do you know who I am?' to which I replied: 'You're my friend, Libby.' " Spurred by intentional questions to inspire descriptive tales of her past, with the help of Google to fill in some of the forgotten pieces, she navigated stories of her life in my company. From the scenery and big white house in North Carolina to meeting Betty White at a Dine \& Dance event in Hollywood's Ambassador Hotel, her stories brought life 
into the previously dim room and light into her eyes. The affective nature of the experience also shifted the ways in which I understood my own role in these moments - as witness to her and her condition, as creative navigator of tough moments of frustration which were relieved in our enmeshment in music, colors, touch, and photographs. I often sat on the floor by her chair, holding one of her beautifully wrinkled hands while she twirled my hair between the fingers of her other. As Reverend Rick described, these CIE moments are important because: 'They are focused on life. Patients need someone who cares about their story, who wants to know about the times they laughed, the times they cried, the people who loved them, and the ways they've loved others.' This was mindfulness, this was presence; and, while I knew the fundamental purpose of my visit was to enhance Libby's holistic health, the connection was really good for me, too. (First author fieldnotes).

The capacity of creative programming to foster a mindful presence that resists narrative foreclosure was continuously evidenced in CIE experiences. Throughout Leon's illness, Patty was able to connect with her parents, both of whom she was losing quickly due to devastating diagnoses. Leon and Eileen had a special relationship and their love for one another was glaringly obvious with every sweet glance, laugh, and kiss. Following one of their afternoon dates, Eileen said, I don't remember a lot of these stories on my own, but when Leon tells our stories, it makes me happy to hear all the places we went and how much we've loved each other. Patty expressed that bearing witness of this love was one thing she would miss most once they were gone, so we used CIE resources to video-record some of their dates. Patty further invested herself in these opportunities by digging through boxes of old photographs and putting together slideshows to guide their shared moments dwelling in the stories of the family narrative. After Leon passed away, Patty overflowed with appreciation - for the time spent with her parents and the gift of having those moments memorialized on video. You just, you just don't think of doing that kind of thing when you're in the midst of managing the illness and taking care of your parents, she reflected. I'm so very glad you were there to think of something that I just couldn't on my own. I will cherish these moments.

In CIE interactions, identities were performed, relationships were consummated, and important conversations unfolded that otherwise may not have occurred. In these spaces, we witnessed what Mattingly ${ }^{2}$ referred to as the narrative shape of hope, hope that is not merely cherished or passively received but actively cultivated, practiced. Through an embodied, aesthetic approach to relationship, CIE participants joined in a shared vulnerability and responsiveness to the humanity of one another. Their capacities to be mindfully present and move with others through experience, to feel with and for one an- other, were fundamentally transformed to be communicable and endlessly shareable, reaffirming and celebrating individuals' fundamental identities as 'creators, 'imaginers, 'and 'makers' in their relational narratives. ${ }^{33}$

\section{Cultivating Meaning-filled Tomorrows}

In response to the significant changes imposed by lifethreatening illness and death, individuals are faced with the task of renegotiating meaning in life. The CIE rooted relational responses in an artful perspective, inspired by what Dewey ${ }^{30}$ described as not one of rationalization in response to this world of mystery, uncertainty, and doubt, but rather one navigated by the insight of imagination. Such was the case for Missy, a hospice patient in her early thirties with two young sons, who spent quite a bit of time in her room writing letters to her boys. She was determined to remain a powerful presence in their lives even after cancer took her life. Missy had a keen awareness that her illness and death would shape her children's futures. She also was aware her children would become constant reminders to her mother of a piece of her history that she had lost too soon. In recognition of this, Missy used the CIE to design a collage she would gift to her mother, crafted with their favorite colors, images, textures, and a photo representative of their mother-daughter bond: a keepsake reminder of their family legacy.

End-of-life circumstances do disrupt and alter life stories, but they do not finalize them. As Freeman ${ }^{19}$ recognized, [e]ven when one has reached what feels like a point of no return, it may nevertheless be possible to move creatively into the future. Joey and Josh, twin teen brothers who requested a CIE photography session when their mother was transferred to the hospice home, knew this to be profoundly true. For, even though their mother's death had been the lowest point of their lives, these young adult men found joy and purpose in capturing lasting images of their mother's love. As we took photos of various tattoos she had inscribed on her body after they were born - their initials, the moon and stars, their favorite pet's name they reciprocated her gentle spirit and caring nature by moving bed linens, monitors, and wires to ensure that her legacy would not be marred by illness. Only weeks after they said their final goodbye, the CIE photographs prompted these brothers to share vivid stories with me; their memories flowed freely, from childhood and their pet duck to the music that helped them heal and their new tattoos in remembrance of their mom. Joey and Josh demonstrated that people have rich histories and hopefilled futures to share that can be spurred by the aesthetic qualities of the world around them. Their aunt explained, something changed in those boys after the three of you spent time together ... It was like they were full of life again, underscoring the powerful effect of the CIE experiences and their capacity to enable individuals to embrace the legacies of those they love and co-construct family 
legacies that fuel rather than constrict the future of their stories.

Death does not mean finality. This is something that Reverend Rick stressed time and again, those left behind have lives intertwined with those they have lost. ... Legacies continue in us. Patrice, the bereavement coordinator, referred to the spaces that CIE created as holy ground, places that were personalized and creatively responsive to individuals' unique experiences and need to account meaningfully for their loss. Dewey ${ }^{30}$ encouraged individuals to move beyond the tendency to beat down or bury painful experiences and, instead, use them as an invitation to reflection.

In recognition of this, the first author and her significant other relied upon narrative imagination and aesthetic appreciation to guide their approach in working as teen leaders for Grace Hospice's annual family-bereavement retreat. These young individuals (four had lost an older sibling or close relative to suicide and one lost a younger sibling to drowning) shared that they often felt misunderstood and intentionally silenced their own thoughts and emotions in effort to be strong for their family. Although their experiences were undeniably tragic, each one desperately wanted to hold fast to positive memories of their loved one. Throughout the weekend they engaged in of a wide range of activities (e.g., a bonfire, sparklers, funny photo session, charades, canoeing, walks through the woods, photography, painting, collages, beaded acronym bracelets) that elicited storytelling occasions in which they thoughtfully reflected on the life legacies of those they had lost. There was something spectacular in the aesthetically rich collaborative space that made room for possible futures previously unimagined. Further, they embraced vulnerability and demonstrated their resiliency as they shared new perspectives gained from their experiences with other family members.

In these various end-of-life contexts, CIE experiences became spaces in which individuals challenged themselves to perceive the potency of immediate circumstance as temporal events that begged significance beyond themselves. As patients and families interacted in these artbased storytelling occasions, they co-constructed their relational stories in edifying ways that unveiled possibilities for their tomorrows. The active performance and building of family legacies invites individuals to attend to the and then of their stories, or from a Deweyan perspective, a concentrated effort to carry the past into the present and future to deepen the moral commitment of cultivating an artful life.

\section{Conclusions}

CIE embraced an artful approach to living and dying. Rather than submitting to the finality of death, volunteers, patients, and patients' family members relied upon their aesthetic sensibilities and narrative imagination as re- sources that enabled them to actively cultivate hope amid the uncertainties and pain inherent in end-of-life circumstances. Individuals' multisensory stories, guided by an impulse of imagination, functioned to move people - not just in an emotive sense, but also in a transformative manner to other perspectives and possibilities. The legacies of lives lost in a medical sense remain powerfully present in histories shared and memories made throughout the course of illness. Relational bonds survive. Futures may be imagined that hold fast to the legacies of those whose lives end before our own.

In the context of end-of-life, the value of stories cannot be over-emphasized. Conjoining imagination and narrative understanding breathes life into living, and dying. Clarity emerges through chaos while complexity is acknowledged; ${ }^{17}$ permanence and change intertwine and coexist as integral supporting elements to one another, ${ }^{34}$ lives and relationships grow in edifying ways as individuals artfully move through temporal moments of disparity and joy. ${ }^{30}$ As evident in CIE moments, the complexity of these circumstances requires an imaginative stance toward the temporal nature of the events and relationships that give shape and meaning to our lives. We are, as Andrews ${ }^{5}$ noted, living, breathing and interacting in the world even while our minds are full of memories and dreams and this is the precise balancing act which defines us as human beings. To ignore these rich aspects of human nature would be to discount some of the most affective features of life.

If we wish to celebrate humanizing approaches to care - to enlarge our capacities to realize the relational depths waiting to be achieved with creative and compassionate adventure - we must admit that we fail ourselves and one another when we reduce our communication to words and sequester the meaningfulness of past stories, present moments, and future possibilities due to the challenges brought on by circumstance. Language is limited. Life and its ending are confusing, chaotic, and messy journeys; they are also beautiful, experienced and expressed in vivid ways. Our stories should reflect this reality. Our relational choices, personal and professional, should have the courage, the audacity, to embrace imagination as a narrative sensemaking resource that is responsive to life's inherent fragility and vulnerability. Real life happens in the difficult and the ordinary of every day - we make it extraordinary, though, and experience what Foster ${ }^{35}$ described as the magic in the mundane when we are willing to put our imaginations to work and actively story our experiences. In doing so, we create edifying relational spaces: where histories and possibilities are intimately tied to the potency of the present; where individuals may navigate experience with a situated, yet dynamic, perspective; where people may be simultaneously rooted in the present moment, while transporting themselves to the stories of their pasts and imagined futures so as to enrich existence with acknowledgement 
that experiences do hold far greater meaning than their temporal tethers.

Imaginative narrative resources offer us the opportunity to pursue more nuanced understandings of what stories do to and for people. We witnessed the aesthetic spirit and impulse of stories, told and performed, working on people. No matter how it manifested - whether the innate desire to play the piano or sing, or perhaps the accepted invitation to paint when someone never thought they would have the chance, a daughter who asks her parents to record stories of their life together, or a hospice nurse who recognizes that her patient needs something more than the details outlined in her hospice care plan - narrative imagination and aesthetic sensibilities worked together in end-of-life settings to actively refuse narrative foreclosure in a context all-too-often misunderstood as being the end.

We hope our portrayal of CIE encourages readers to explore what is accomplished by the stories people perform and tell and what is made possible by the multisensory modalities with which they are created and shared. These imaginative endeavors paved way for relational practices of hope that transcended circumstance and served the critical functions of transcending chasms, nurturing mindfulness and presence, and cultivating legacies and meaning-filled tomorrows. In recognizing the potentials of narrative imagination and creative forms of communication, we may attend to people with grace in the vulnerable experiences of life, offer practical opportunities to strengthen resiliency, enhance the manner in which care is cultivated in the health professions, embrace the essence of being human amid the very real difficulties that life poses, and traverse temporalities in ways that reveal and create significance of our life stories and relationships.

\section{References}

1. Kübler-Ross E. Death with dignity: An inquiry into related public issues. Hearing before the Spec Comm on Aging. 92nd Cong., 2nd Sess. (Aug. 7, 1972). Available from: https://www.aging.senate.gov/imo/media/doc/publications/8 71972.pdf Accessed: October 2019.

2. Mattingly C. The paradox of hope: Journeys through a clinical borderland. Berkeley: University of California Press; 2010.

3. Bruner JS. Actual minds, possible worlds. Cambridge (MA): Harvard University Press; 1986.

4. Sharf BF, Harter LM, Yamasaki J, Haidet P. Narrative turns epic: Continuing developments in health narrative scholarship. In Nussbaum J, Parrott R, Thompson T. (eds). Handbook of health communication. 2nd ed. Mahwah (NJ): Routledge; 2011: p. 36-51.

5. Andrews M. Narrative imagination and everyday life. Oxford: Oxford University Press; 2014.

6. Sharf BF. Observations from the outside in: Narratives of illness, healing, and mortality in everyday life. J Appl Commun Res 2009;37:132-9.

7. National Hospice Foundation [Internet]. About NFH: Our vision. Available from: https://www.nationalhospicefoundation.org.

8. Connor SR. Hospice: Practice, pitfalls, and promise. Washington, D. C.: Taylor \& Francis; 1998.

9. American Hospice Foundation [Internet]. Learning about hospice. Available from https://americanhospice.org/learning-about-hospice/

10. Roscoe LA., Tullis JA. The meaning of everything: Communication at the end of life. J Med Pers 2015;13:75-81.

11. Charon R. Narrative medicine as witness for the self-telling body. J Appl Commun Res 2009;37:118-31.

12. Clark D. Cicely Saunders - founder of the hospice movement: Selected letters 1959-1999. New York: Oxford University Press; 2005.

13. Frank AW. The wounded storyteller. Chicago: University of Chicago Press; 2013/1995.

14. Sharf BF, Vanderford ML. Illness narratives and the social construction of health. In Thompson TL, Dorsey A, Miller KI, Parrott R, editors. Handbook of health communication. Mahwah (NJ): Erlbaum; 2003. p. 9-34.

15. Aleman MW, Helfrich, KW. Inheriting the narratives of dementia: A collaborative tale of daughter and mother. J Fam Commun. 2010;10:7-23.

16. Roscoe LA, Barrison P. Dilemmas adult children face in discussion end-of-life care preferences with their parents. Health Commun. 2018.

17. Frank AW. Letting stories breathe: A socio-narratology. Chicago: University of Chicago Press; 2010.

18. Ricoeur P. Time and narrative. McLaughlin K, Peelauer D, translators. Chicago: University of Chicago Press; 1984.

19. Freeman M. Narrative foreclosure in later life: Possibilities and limits. In Kenyon G, Bohlmeijer E, Randall WL, editors. Storying later life: Issues, investigations, and interventions in narrative gerontology. Oxford: Oxford University Press; 2011. p. 3-19.

20. Montgomery K. How doctors think: Clinical judgment and the practice of medicine. Oxford: Oxford University Press; 2006.

21. Dain AS, Bradley EH, Hurzeler R, Aldridge, MD. Massage, music, and art therapy in hospice: Results of a national survey. J Pain Symptom Manage. 2015;49:1035-41.

22. Ellingson LL. Engaging crystallization in qualitative research: An introduction. Thousand Oaks (CA): Sage; 2009.

23. Atkinson P, Coffey A. Revisiting the relationship between participant observation and interviewing. In: Gubrium JF, Holstein JA, editors. Postmodern interviewing. Thousand Oaks (CA): Sage; 2003. p. 109-22.

24. Berg BL. Qualitative research methods for the social sciences. 7th ed. Boston: Pearson Education; 2009.

25. Charmaz K. Grounded theory in the 21 st century: Applications for advancing social justice studies. In: Denzin NK, Lincoln YS, editors. The Sage handbook of qualitative research 3rd ed. Thousand Oaks, CA: Sage; 2005. p. 507-35.

26. Reissman CK. Narrative methods for the human sciences. Thousand Oaks (CA): Sage; 2008.

27. Boje DM. The storytelling organization: A study of story performance in an office-supply firm. Adm Sci Q 1991;36:106-26.

28. Mollica RF. Healing invisible wounds: Paths to hope and recovery in a violent world. Nashville: Vanderbilt University Press; 2006.

29. Bern-Klug M. Introduction. In: Bern-Klug M, editor. Transforming palliative care in nursing homes: The social 
work role. New York: Columbia University Press; 2010. p. $1-5$.

30. Dewey J. Art as experience. New York: Penguin Group; 1980/1934.

31. Whalen D. Meeting your metaphor: The use of the arts and the imagination with dying persons. In Perry Magniant RC, editor. Art therapy with older adults: A sourcebook. Springfield (IL): Charles C Thomas Publisher; 2004. p. 101-21.
32. Frank AW. The renewal of generosity: Illness, medicine, and how to live. Chicago: University of Chicago Press; 2004.

33. Scarry E. The body in pain: The making and unmaking of the world. New York: Oxford University Press; 1985.

34. Burke K. Permanence and change: An anatomy of purpose. 3rd ed. Berkeley: University of California Press; 1984/1954.

35. Foster E. Communicating at the end of life: Finding magic in the mundane. Mahwah (NJ): LEA; 2007. 